\title{
El peso de Sodoma: el caso del doctor Manuel Barros de San Millán como arma política en el virreinato peruano a fines del siglo XVI*
}

\section{The ignominy of Sodom: the case of Dr. Manuel Barros de San Millán as political weapon in the Viceroyalty of Peru at the end of the $16^{\text {th }}$ century}

GIANCARLO MORI BOLO

Pontificia Universidad Católica del Perú

gmorib@pucp.edu.pe

\section{RESUMEN}

El presente artículo analiza el papel que tuvo el proceso por sodomía del doctor Manuel Barros de San Millán (1532- ¿?), presidente de la Audiencia de Quito, en la crisis política desatada por la imposición de la alcabala a finales del siglo $X V I$ en el virreinato peruano. De carácter intransigente, Barros fue un burócrata con una carrera colmada de conflictos y choques con otros poderes del Perú colonial. Desde su llegada en 1560, su falta de tino solo entorpeció su labor y lo expuso a venganzas de diversa indole. Por eso, cuando su exesclavo declaró haber iniciado sus prácticas sodomiticas con él, sus enemigos no dudaron en usar esta acusación en su contra. Como se demostrará, el proceso contra Barros por haber cometido el pecado nefando tuvo como objetivo deslegitimarlo politicamente al cuestionar su masculinidad. Con ello lograron, finalmente, desterrarlo para siempre del Nuevo Mundo.

${ }^{*}$ Este artículo se basa en la tesis para optar por el título de licenciatura en Historia en la Pontificia Universidad Católica del Perú. Agradezco los comentarios de las doctoras Margarita Suárez y Magally Alegre durante el proceso de esta investigación, y de los lectores anónimos.

hISTORIOA XLIV.1 (2020): 7-40 / ISSN 0252-8894 
Palabras clave: Manuel Barros, sodomía, masculinidad, sexualidad, Quito, Alcabala.

\section{ABSTRACT}

This article discusses the role of the sodomy trial of Dr. Manuel Barros de San Millan (1532-?), president of the Audiencia of Quito, in the political crisis triggered by the introduction of an alcabala tax at the end of the 16th century. Barros was an intransigent bureaucrat whose career was riddled with confrontations with other authorities in colonial Peru. Since his arrival in 1560, his tactlessness hindered his work and exposed him to different kinds of retribution. Against this backdrop, when his former slave claimed to have engaged in sodomitical practices with him, his enemies used the opportunity to attack him. The process against Barros for indulging in the unspeakable vice aimed at delegitimizing him politically by debasing his masculinity. In this way, his enemies succeeded in banishing him permanently from the Americas.

Keywords: Manuel Barros, Sodomy, masculinity, sexuality, Quito, Alcabala.

S in lugar a duda, el doctor Manuel Barros de San Millán se encuentra entre los personajes más controvertidos del virreinato del Perú de fines del siglo XVI. Con una larga experiencia jurídica, Barros inició su carrera como oidor de la Audiencia de Guatemala en 1560. Su paso por diferentes audiencias lo hicieron acreedor de muchas enemistades y odios políticos. Una muestra de esto fue su designación como presidente de la Audiencia de Quito en 1587. En esta localidad, entró en conflicto con múltiples grupos del poder colonial, situación que llegaría a su punto crítico, como se verá más adelante, con el levantamiento de la alcabala en 1590. En ese contexto, Barros fue procesado por sodomía en la ciudad de los Reyes. Este juicio fue uno de los más sonados tanto en Lima como en las diferentes audiencias donde ejerció como oidor. Por esta razón, no fue sorpresivo que el Consejo de Indias interviniese para evitar un escándalo mayor. 
El caso de Barros es una de las pocas oportunidades donde se observa, con mucha claridad, la relación entre la sexualidad y el poder en el mundo colonial. Por esta razón, el proceso se convierte en el espacio idóneo para analizar una sexualidad no normativa frente a lo establecido como adecuadamente masculino en el virreinato peruano. Además, permite entender cómo las disputas políticas hicieron uso de la sexualidad como ataque hacia determinados sujetos en la búsqueda por frenar su poder.

Pese a tener esta provechosa situación, la historiografía no ha examinado estas dos dimensiones en conjunto. Por un lado, algunos autores solo han estudiado el papel de Barros como funcionario de la corona y su responsabilidad política frente al levantamiento quiteño por la alcabala. ${ }^{1}$ Por otro, los estudios recientes sobre la sexualidad en el virreinato del Perú tan solo han utilizado el caso en la búsqueda de ciertos patrones alrededor de la masculinidad; dejando de lado la importancia de la posición privilegiada de Barros y el contexto político de este caso. ${ }^{2}$

Este artículo propone que los enemigos de Barros buscaron deslegitimarlo políticamente a través del juicio por haber cometido el pecado nefando. En ese sentido, primero, se examinará la controvertida carrera de Barros. Asimismo, se analizarán las tres partes de la denuncia formal y la manera como criticaron diferentes características del magistrado. A partir de esto, se evidenciará la relación entre este proceso por sodomía y el contexto de crisis política en Quito. Por último, se observarán las consecuencias de este proceso en la posición de Barros como autoridad del virreinato peruano.

\section{UN MAGISTRADO PECULIAR}

De carácter conflictivo, Barros inició su carrera como muchos otros funcionarios del siglo XVI. Nació en Segovia en 1532 y estudió leyes en las universidades de Alcalá de Henares y Salamanca. ${ }^{3}$ En esta última, obtuvo el grado de doctor en derecho canónico y civil. Su trabajo lo llevó

2 Molina 2010a, 2010b, 2011, 2013, 2014a, 2014b y 2017.

3 Bermúdez Plata 1940-1986, II: 66. 
a ser parte de los fundadores de la Universidad de Osuna. Además, fue nombrado administrador de las tierras del duque de Osuna. ${ }^{4}$ Gracias a esta conexión, Barros fue nombrado oidor de la Audiencia de Guatemala en 1560. Su carrera lo llevaría por las jurisdicciones de Panamá, Charcas, como oidor, y Quito, como presidente de Audiencia. Durante este tiempo, Barros tuvo algunas disputas y cuestionamientos por sus prácticas sexuales.

En el Nuevo Mundo, sus principales preocupaciones estuvieron centradas en el buen trato a los naturales y los delitos contra la moral. Esto último lo llevaría a tener conflictos en las audiencias de Guatemala y Panamá. Su falta de tino en la persecución de este tipo de delitos fue el origen de las constantes quejas enviadas por los encomenderos a las autoridades en la metrópoli. ${ }^{5}$ En Panamá, este malestar provocó que, en 1567, allí y en sus alrededores amanecieran llenas de libelos acusando a Barros de cometer el pecado nefando con su esclavo Pedro; situación que acabaría con la ejecución de un inocente y la fuga del verdadero culpable. ${ }^{6}$ En 1569, Barros fue nombrado oidor de la Audiencia de Charcas, donde rápidamente entró en conflicto con otras autoridades. Influenciado por los debates en torno a los indios durante sus años como estudiante universitario, Barros defendió fuertemente el buen trato a los naturales. Su visión alrededor del maltrato indígena lo convirtió en enemigo del oidor Juan de Matienzo y del virrey Francisco Toledo. En 1578 , sumado a algunos problemas personales con Matienzo, Barros fue acusado de obstruir la justicia y de haber cometido el pecado nefando. ${ }^{7}$ Esta persecución política se detuvo con la muerte de Matienzo al año siguiente.

Seguro de que los rumores de todos sus conflictos llegarían a la península, el doctor Barros envió una larga explicación al Consejo de Indias en 1581. Además de señalar que todas las acusaciones eran falsas, estableció que Toledo era responsable de los conflictos políticos en la Audiencia y

4 Archivo General de Indias [en adelante AGI], Escribanía 917B, f. 353v.

5 AGI, Panamá 13, R. 8, N. 11.

6 AGI, Escribanía 917B.

7 Murra 1998: 435. 
de todos los maltratos que recibían los indios en Charcas. ${ }^{8}$ Sin embargo, sabiendo que sería más oportuno explicarlo personalmente, Barros se embarcó a España en 1585. Dos años más tarde, y pese a las enemistades acumuladas, Barros fue nombrado presidente de la Audiencia de Quito. Fue en este tribunal donde los problemas políticos llegaron a su punto crítico, pues, como se verá más adelante, su intransigencia e incapacidad para dialogar con los poderes locales consiguieron resurgir los antiguos rumores sobre sus prácticas sexuales.

\section{EL JUICIO EN LA CIUDAD DE LOS REYES}

El 3 de julio de 1590, el alcalde ordinario Pedro de Santillán hizo comparecer al esclavo Andrés Cupín por haber cometido el pecado nefando con otros esclavos en la cárcel de Lima. ${ }^{9}$ En el proceso, Xacome Carlo, su curador, no pudo demostrar su inocencia, pues las acusaciones contra Cupín eran claras y directas. En su testimonio, Cupín explicó que había iniciado sus prácticas sodomíticas con el doctor Barros en Charcas. La gravedad de esta acusación provocó la suspensión de su sentencia de muerte por ser considerado un testigo crucial en una posible investigación contra Barros.

Después de ratificar el testimonio del esclavo, la decisión pasó a manos del virrey García Hurtado de Mendoza, marqués de Cañete. ${ }^{10}$ A la par, las indiscreciones del alcalde Santillán ocasionaron que ciertos sectores de la sociedad limeña conociesen de la confesión del esclavo y de la preparación de un caso contra Barros. El mercader Luis de San Millán, pariente de Barros, informó al magistrado sobre esta situación e intervino a su favor. ${ }^{11}$ Para fines de 1591, la situación se había tornado extraña, pues Cupín intentó retractarse de su acusación en tres ocasiones, pero las autoridades virreinales no quisieron recibir su declaración. Cupín

8 AGI, Charcas 16, R. 20, N. 85.

9 AGI, Escribanía 917B.

${ }^{10}$ AGI, Escribanía 499B, f. 54-58 v.

${ }^{11}$ AGI, Escribanía 917B, f. 276. 
manifestó que su testimonio era falso, que todo lo dijo porque Julio Matos de Norońa, ${ }^{12}$ otro reo, lo había persuadido para declarar eso.

En febrero de 1592, Gabriel de Arriaga, en representación del presidente de la Audiencia de Quito, informaba a Madrid sobre la turbia situación. ${ }^{13}$ El procurador informó sobre los sucesos entre Cupín y Matos. Además, advirtió que el curador del esclavo era enemigo de Barros, ya que había sido desterrado durante la visita realizada por Barros a Quito. A finales del mismo año, en una real cédula, Felipe II ordenó al virrey crear una comisión para la investigación del caso. ${ }^{14}$

Esta comisión fue presidida por el mismo marqués de Cañete y conformada por los oidores, el doctor Martín de Avendaño y el licenciado Juan Velásquez de Espina; y los alcaldes de Crimen, el doctor Juan Fernández de Recalde y los licenciados Francisco Coello y Juan de Villela. Entre sus primeras acciones, ordenaron cambiar de cárcel a Cupín y mandaron a arrestar a Pedro Gómez y Roque Marroquí, exesclavos de Barros, quienes fueron apresados en Chuquisaca. ${ }^{15}$ Sin embargo, a pesar de las torturas, las declaraciones de ambos esclavos no fueron contundentes.

Durante el proceso, los testigos a favor del doctor Barros aseguraron que Matos de Noroña fue sobornado por el virrey para persuadir a Cupín. Cuando salieron a la luz las conversaciones entre ambos presos, Matos se dio a la fuga. Sin ayuda de las autoridades, Luis de San Millán logró atrapar al fugitivo. Entre sus objetos, Matos tenía un documento firmado por el marqués de Cañete, donde se le daba licencia para poder tomar cualquier navío sin ningún impedimento. Después de entregarlo al alcalde, se exigió que se custodiara con mayor detenimiento al preso. No obstante, esa misma noche, Matos escapó y no se supo de su paradero hasta algunos años más tarde. ${ }^{16}$

${ }^{12}$ Según parece, Matos fue quien convenció al esclavo de acusar al presidente de haber cometido el pecado nefando (AGI, Escribanía 917B).

${ }^{13}$ Ib.: f.1.

${ }^{14}$ Ib.: f. $289 \mathrm{v}$.

${ }^{15} \mathrm{Ib}$.

${ }^{16}$ Años después, Matos fue acusado por la Inquisición de usurpar las funciones de clérigo. Como consecuencia, fue juzgado por esa institución (AGI, Escribanía 917B: f. 611-614). 
El 4 de enero de 1593, la comisión ordenó la detención del oidor. ${ }^{17} \mathrm{El}$ 6 de julio, en una larga misiva, Barros denunció que toda esta situación fue provocada por los odios y resentimientos de algunas personas en Quito; incluyendo al licenciado Esteban Marañón, quien, meses atrás, había llegado, como visitador, para calmar las quejas contra el impuesto de la alcabala. Marańón había suspendido a Barros de su cargo debido a las protestas. Asimismo, este último no entendía por qué el vicesoberano insistía en continuar con el caso por sodomía si el testimonio de Cupín era falso. Por último, Barros suplicaba no hacer el viaje a Lima debido a su avanzada edad. ${ }^{18}$ Pese a todo, la comisión no tomó esto en cuenta y reafirmó su decisión.

Intuyendo que el fallo no cambiaría, Barros fue escoltado a la ciudad de Los Reyes. El 27 de agosto de 1594, a tres leguas de la capital virreinal, nuestro personaje y la delegación que salió en su búsqueda se encontraron. Por orden de la comisión, Barros fue acompañado a la chacra del licenciado Diego Barrionuevo de Rivera, que fue designada como su prisión, y ahí se le tomó su confesión algunos días después. ${ }^{19}$

El 7 de setiembre de 1594, el licenciado Ferrer de Ayala, fiscal de la Audiencia, presentó la acusación formal contra Barros. ${ }^{20}$ Inmediatamente, Pedro Ortiz de Valdelomar, procurador de Barros, redactó un largo memorial donde, principalmente, desestimaba la acusación de Cupín. Por una parte, porque sus declaraciones nacieron en un ambiente de confusión y, por otra, porque las descripciones de las relaciones sexuales eran imprecisas. Ortiz desechó el testimonio de Cupín exponiendo que

declara que vino a traerle las piernas, había de ser vestido y así se presume, pues no declara que estaba desnudo y por lo menos será menester de desnudarse y quitarse los calzones para cometer el pecado. Dice también que dormido tuvo acceso con él, mi parte, y esto repugna y es de todo punto

\footnotetext{
${ }^{17}$ Ib.: f. 338v.

${ }^{18}$ Ib.: f.344- 346v.

${ }^{19}$ Ib.: f. 351.

${ }^{20}$ Ib.: f. 360.
} 
imposible. De estas disonancias y repugnancias parece que como es mentira lo que depone no declara ni dice que hecho que pudo pasar. ${ }^{21}$

Para el procurador, las contradicciones se dieron porque Cupín nunca describió en qué momento se desnudó y, sobre todo, no se podía tener certeza del coito si es que el esclavo estuvo dormido. Con respecto a la acusación de que Barros había mantenido relaciones sexuales con Gómez, el procurador dijo que no debían contar el testimonio de Tomás Luis ni las habladurías en Panamá, pues eran especulaciones de los enemigos de Barros, quienes solo querían verlo fuera de sus jurisdicciones. ${ }^{22}$

Por su parte, el fiscal solicitó hacer una investigación exhaustiva en todas las audiencias donde Barros se había desempeñado como representante de la Corona. Esta situación provocó una larga discusión entre las partes, pues el procurador de Barros veía innecesaria la búsqueda de tan graves delitos. Asimismo, más información solo traería mayor escándalo al proceso, pues la noticias de lo que sucedía en Lima ya habían llegado a Quito y Charcas. De manera que la dilación del caso era contraproducente para la honra de Barros y su familia. ${ }^{23}$

Siendo de poca utilidad, la comisión ordenó la ejecución de Cupín. Por orden del virrey, fray Antonio de Martínez fue el único religioso que pudo acercarse al esclavo. La tarde del 11 de octubre de 1594, Cupín fue sacado de la cárcel y llevado al campo de San Lázaro para ser ajusticiado. Mientras se dirigía a su destino, un pregonero divulgaba su delito. Esta sentencia llamó mucho la atención, lo que provocó que el lugar estuviese repleto de limeños. Viendo la multitud, el esclavo declaró que no había cometido el pecado nefando con el doctor Barros, ni el doctor con él, que todo lo dijo presionado por Matos. Además, suplicó a los asistentes fueran testigos de esta declaración. Por último, Cupín se disculpó con Barros por el dańo causado. Al terminar, se le dio garrote y su cuerpo fue incinerado en la hoguera. ${ }^{24}$

${ }^{21}$ Ib.: f. $367-367 \mathrm{v}$.

22 Ib.: f. $368 \mathrm{v}$.

${ }^{23}$ Ib.: f. 380-386.

${ }^{24}$ Ib.: f. 441-441v. 
A inicios de noviembre de ese año, el procurador de Barros presentó tres reales cédulas, por las cuales se exigía que la comisión trabajara con mucho mayor cuidado y rapidez en el caso. Además, se demandó el envío del proceso con una recomendación de sentencia, pues sería solo el Consejo de Indias el que tomaría la decisión final con respecto a Barros. ${ }^{25}$ Aprovechando la situación, Ortiz de Valdelomar exigió la entrega de la última confesión de Cupín y que la retractación fuese enviada a España.

Entre diciembre de 1594 y enero de 1595, fueron presentados varios testigos a favor de Barros, quienes afirmaron haber escuchado la confesión pública de Cupín. Durante el mismo periodo, el fiscal se encargó de recolectar testimonios en diferentes regiones del virreinato. A finales de enero, Luis de San Millán pagó la fianza, liberando a Barros con la condición de permanecer en Lima. El 16 de febrero, llegó una real cédula para que todos los documentos del caso fuesen enviados a la metrópoli.

Lamentablemente, el final del caso se vuelve confuso desde este punto. Lo que sí se sabe es que el veredicto de todos los participantes de la comisión fue enviado a la península, junto con el caso. Según las investigaciones de Bernard Lavallé, Barros fue conducido devuelta a España. Ahí, el Consejo de Indias examinó tanto la visita realizada por Esteban de Marañón, como su caso por sodomía. Sin embargo, para Lavalle, se prefirió no ahondar más en el tema de las alcabalas, porque pondría en evidencia los malos manejos de algunas autoridades del virreinato. Barros, entonces, fue acusado por el fiscal del Consejo por sodomía y por sus cuestionamientos de los justos títulos en 1597. Como resultado, Barros fue sentenciado al pago de 7000 ducados y al destierro de las Indias. ${ }^{26}$

\section{EL NEFANDO CRIMEN DE BARROS}

Durante el siglo XVI, el pecado nefando fue definido como todo «acto mediante el cual se derramaba el semen en un vaso o recipiente no apto para la procreación». ${ }^{27}$ Este acto iba en contra de la continuidad creativa,

\footnotetext{
${ }^{25}$ Ib.: f. 422, 424.

${ }^{26}$ Lavallé 1997: 199.

27 Camba 2011.
} 
entendida como un proceso donde la naturaleza y el hombre prolongan el acto divino. Con ello, la sodomía se constituyó como el pecado por antonomasia, ya que atentaba directamente contra la imagen de Dios. $\mathrm{Al}$ caer en este pecado, se rechazaba la invitación a ser socio en la tarea creadora. ${ }^{28}$ De esta forma, el acto contra natura fue entendido como un atentado contra Dios, uno mismo y el prójimo. ${ }^{29}$

En su jerarquía del pecado, Santo Tomás de Aquino clasificó la sodomía como el peor de los pecados de lujuria. Además, de acuerdo al pensamiento teológico, el abominable pecado fue catalogado dependiendo del sexo de sus participantes. Durante el Concilio de Trento, se ratificaron las ideas en torno a este pecado basándose en la argumentación de los padres de la Iglesia y en el análisis de algunos pasajes bíblicos. ${ }^{30}$

El desarrollo jurídico del nefando crimen estableció sus propias particularidades. Esta transgresión fue definida como un delito de lesa majestad y un crimen atroz. ${ }^{31}$ Determinar la sodomía como un delito de lesa majestad tuvo dos aristas. Por un lado, las leyes penales configuraron como delito todo lo que Dios determinaba como tal, el concepto del Deus legilator. ${ }^{32}$ Así, la sodomía constituyó una ofensa de lesa majestad divina. Por otro, su peligrosidad social fue la base con la cual los intereses del rey, como representación del cuerpo social, fueron afectados. ${ }^{33}$ Se trató, pues, de una ofensa de lesa majestad humana. Con ello, el abominable pecado se consolidó como un crimen contra las dos majestades dentro de la ley penal.

Asimismo, el derecho castellano definió como crimen atroz todo delito que agraviara severamente el orden político, religioso o económico. ${ }^{34} \mathrm{El}$ objetivo de determinar una transgresión como tal significó garantizar «el

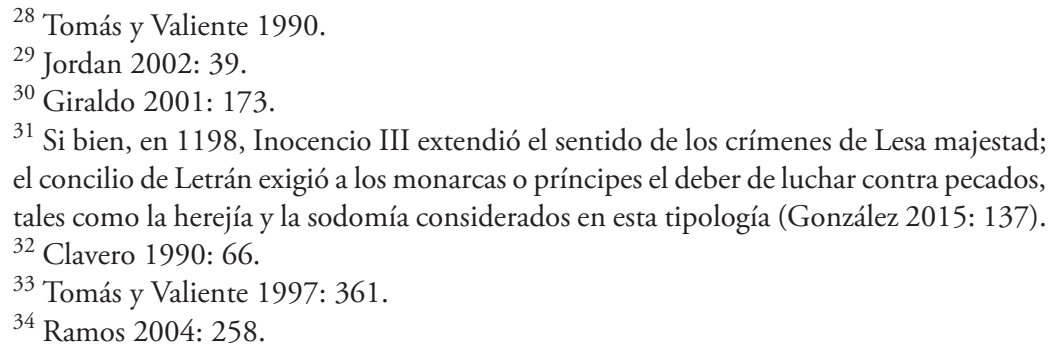


respeto de tres valores fundamentales: la majestad humana o del rey, la majestad divina o unidad religiosa, y la naturaleza en el orden sexual». ${ }^{35}$ Así, fueron decretados como pertenecientes a esta categoría la falsificación de monedas, la herejía, la traición, el asesinato y la sodomía. Finalmente, las leyes de Indias determinaron que en estos reinos el nefando crimen solo fuese competencia del fuero civil. Con ello, la Inquisición solo tuvo jurisdicción en casos que comprometieran al clero.

Como se ha mencionado antes, en setiembre de 1594, el fiscal presentó la acusación formal contra Barros por haber cometido el nefando crimen. Esta acusación estaba dividida en tres partes. La primera fue haber cometido el pecado nefando con Andrés Cupín en Charcas. La segunda, haberlo cometido con Pedro Gómez en Panamá y en Charcas; $y$, por último, por haber liberado y favorecido sodomitas ${ }^{36}$. Cada una de ellas representó un ataque directo a la hombría y autoridad de Barros.

\section{ANDRÉS CUPIN, EL VIR Y LAS MASCULINIDADES DISIDENTES}

En su testimonio, Andrés declaró que:

siendo esclavo del doctor Barros, estando por oidor de la Audiencia real de las Charcas, podrá haber catorce o quince ańos, siendo este confesante muchacho de edad de catorce años poco más o menos, cometió el dicho pecado [nefando] el dicho doctor [Barros] con este confesante haciéndole dormir en el aposento donde dormía el dicho doctor Barros a los pies de su cama donde el dicho doctor cometió el dicho pecado haciéndole acostar en la misma cama donde estaba acostado hasta media noche oscuras el dicho aposento echándose carnalmente con este confesante metiéndole su miembro por el culo e cuando se lo sacaba se sentía este confesante mojado y esto hizo el dicho doctor Barros con este confesante más tiempo de cuatro meses y en el dicho tiempo durmió con el muchas veces y noches cometiendo el dicho pecado. ${ }^{37}$

Esta declaración fue la única acusación directa contra Barros. Dentro del proceso, las otras acusaciones solo representaron actitudes del magis-

${ }^{35}$ Ib.: 265 .

${ }^{36}$ AGI, Escribanía 917B.

${ }^{37}$ AGI, Escribanía 499B, f.21 v. 
trado con algunos esclavos o soldados. Muy a pesar de la búsqueda del fiscal, ningún otro implicado aseguró haber tenido relaciones sexuales con Barros. Por esta razón, esta parte de la denuncia tuvo como finalidad mermar la masculinidad de Barros. ${ }^{38}$ En ese sentido, el interrogatorio y los testimonios respondieron a una lógica de ataque y defensa de la hombría. De forma que el objetivo de su defensa fue demostrar la cercanía de Barros a lo adecuadamente masculino.

A lo largo del siglo XVI, la corona española buscó delimitar una masculinidad hegemónica como parámetro para conservar el orden y controlar a la población. ${ }^{39} \mathrm{El}$ discurso imperial pretendió imponer la cristiandad, la autoridad regia y ensalzar la virilidad en el hombre. Moralistas, como Alfonso de Castro, ${ }^{40}$ definieron al vir hispano como un pío gentilhombre, honorable, gallardo guerrero, vasallo fiel, devoto, temeroso de Dios, fuerte, seductor, casado, valeroso y de una potencia sexual indiscutible. ${ }^{41}$ De este modo, estos atributos de la masculinidad moderna se construyeron bajo estos tres ejes: el cristianismo, el honor y el vigor sexual.

En primer lugar, la cristiandad fue un punto clave en el nuevo discurso de la hombría. Los tratadistas españoles fijaron que este gentilhombre debía defender las costumbres religiosas y expandirlas en el Nuevo Mundo. ${ }^{42}$ La relación entre el valor cristiano y la hombría se consolidó bajo la reconquista española, donde librar el territorio del yugo

38 Se define masculinidad como un momento dentro de las relaciones de género, donde hombres y mujeres buscan su lugar en su interacción, y que tiene consecuencias en lo físico, psicológico y cultural. Se infiere que la masculinidad es, también, una diferenciación intragénero; es decir, cómo los hombres perciben las diferencias entre ellos mismos. Además, se reconoce una multiplicidad de masculinidades, que se construyen sobre la base de otras categorías como raza y clase social (Connell 2003: 104-109).

39 Garza 2002.

${ }^{40}$ Alonso de Castro (1495-1558), teólogo franciscano perteneciente a la segunda escolástica española, fue consejero de la Casa Real Española durante el siglo XVI. Fue enviado al Concilio de Trento, donde tuvo una participación muy activa en favor de las reformas planteadas. Cercano a los reyes Carlos I y Felipe II, influenció con su pensamiento la corte espańola de su época (Redworth 2004).

${ }^{41}$ Garza 2002: 36, 72; Molina 2011: 186.

42 Garza 2002: 73. 
musulmán fue acción clave. ${ }^{43}$ Durante este proceso, los prejuicios contra los moros, algunos basados en historias relacionadas con la sodomía, ${ }^{44}$ fueron utilizados como propaganda católica. ${ }^{45}$ Esta idea de asociar al hereje con la sodomía se transportó fácilmente a las Indias. ${ }^{46}$

El cumplimiento de los sacramentos fue otra forma de expresar una adecuada masculinidad. Dentro de las propuestas tridentinas, la Iglesia afianzó un sistema moral basado en el control de la sexualidad. ${ }^{47}$ Esta actividad debía estar vinculada estrictamente al ámbito de la procreación, es decir, a la institución familiar. El matrimonio significó, para la Iglesia y el Estado, la base de las socializaciones política y moral. ${ }^{48}$ Por ello, la defensa y cumplimiento del sacramento matrimonial constituyeron la defensa del modelo social, impuesto por ambos poderes coloniales. ${ }^{49}$

Como segundo aspecto, el honor fue una importante característica dentro de la sociedad hispana. Este concepto fue un complejo código social que establecía los criterios para el respeto público. Además, significó el reconocimiento de la integridad individual y familiar. ${ }^{50}$ En ese sentido, la honra entrelazaba las ideas de nobleza, cristiandad, privilegio, cargo y tratamiento hacia una persona o grupo. El honor se constituyó como un molde para el comportamiento de hombres y mujeres con el objetivo de que un individuo sea identificado y apreciado por el resto de la sociedad. Por ende, el conocimiento público de estas prácticas sexuales resquebrajaba el honor. ${ }^{51}$

Como tercer eje, el vir español exaltaba la virilidad masculina controlada. Valiente, fuerte y seductor fueron adjetivos asociados con este nuevo

${ }^{43}$ Molina 2011: 197.

${ }^{44}$ En la cultura católica hispana, una de las historias que condenan la sodomía y la asocian con el hereje es el martirio de San Pelayo. Para más información, véase Jordan 2002: 23- 49 .

45 Stavig 2003: 142.

${ }^{46}$ Molina 2011: 197.

${ }^{47}$ Ghirardi 2009: 245.

${ }^{48}$ Reyes 2010: 60.

${ }^{49}$ Ghirardi 2009: 266.

${ }^{50}$ Seed 1991.

${ }^{51}$ Burkholder 1999: 18. 
hombre. Desde las guerras de reconquista, la literatura de la época glorificaba al héroe y la violencia por la defensa de la fe. Además, la imagen del hombre como cabeza de familia marcó su lugar preponderante frente a la mujer y lo femenino. En este sentido, el espacio americano brindó la oportunidad de perpetuar esta idea. ${ }^{52} \mathrm{~A}$ su vez, las relaciones interétnicas expandieron una cultura del amancebamiento en los espańoles a lo largo del siglo XVI. Con ello, se procuró una masculinidad, entendida como virilidad controlada, donde se exaltaba la potencia sexual dirigida, exclusivamente, a lo femenino. El vir español fue, entonces, la medida con la que los hombres fueron juzgados por sus pares y, en general, por la sociedad. Como imposición de las autoridades españolas, esta imagen fue nutrida con características de orden religioso, moral y sexual. Todas ellas enraizadas en la cultura hispana. Más allá de las sentencias legales, socialmente también existieron críticas a los individuos que se alejaban del parámetro impuesto por este hombre ideal. Por consiguiente, el ser acusado de cometer el nefando crimen significaba un duro ataque social al implicado.

En el caso de Barros, es posible notar la presencia del discurso del vir español. A través de los testimonios, es evidente una estricta actitud frente a cómo debió comportarse un presidente de Audiencia. Estos testimonios se originaron de una variedad de individuos del virreinato. Por consiguiente, las presiones por cumplir los parámetros masculinos fueron realizadas por la sociedad colonial en su conjunto. En el desarrollo de este juicio, se puede dividir estas declaraciones bajo los tres ejes centrales del vir: religiosidad, honor y virilidad.

La religiosidad de Barros fue uno de sus argumentos más sólidos. Todos los testigos a su favor afirmaron que era un buen cristiano y un hombre muy piadoso. Por ejemplo, el licenciado Alonso Fernández de Bonilla, inquisidor y arzobispo de México, aseguró que «ha sido hombre de particular celo en extirpar pecados públicos y castigar delitos, reduciendo la república a paz y quietud y muy recto y limpio juez y muy

52 Por ejemplo, la sumisión americana y su relación con el mito de la Malinche han sido trabajados por Medina (2004). 
entero en hacer justicia sin excepción de personas». ${ }^{53}$ Así mismo, Gómez y Marroquí, exesclavos del magistrado, indicaron que Barros siempre fue un hombre de una fuerte religiosidad. ${ }^{54}$

Sin embargo, es posible poner en duda esta fuerte religiosidad. Barros debía cuidar su imagen ante las autoridades metropolitanas, así, su perfil estaba constantemente alimentado por sus acciones y sus cartas. Al ser un hombre muy culto, no le fue difícil escribir e incluir referencias religiosas en sus textos. A mediados de 1593, se confiscaron ciertos documentos entre Barros y su primo. En general, las cinco cartas denotaron este supuesto fervor. Igualmente, sus escritos públicos fueron redactados con un alto carácter religioso. ${ }^{55}$ Por experiencias anteriores, Barros sabía que su correspondencia podía ser utilizada en su contra; razón por la cual debió cuidar, incluso, lo escrito en su correspondencia personal.

Como se ha hecho notar anteriormente, el honor de Barros había sido puesto en tela de juicio muchos años atrás. Esta mala fama provenía de su desempeño como oidor en Panamá. Los líbelos, donde se afirmaba que había cometido el pecado nefando con su esclavo Pedro, fueron el inicio de una cadena de rumores que lo perseguirían en su estancia en el Nuevo Mundo. La noticia llegaría hasta Charcas, donde enfrentó su primera demanda por sodomía. Sin sentencia, este litigio se encargó de mantener vivos los rumores alrededor de sus prácticas sexuales durante la siguiente década. Así, para 1590, el honor sexual de Barros volvió a ser puesto en duda gracias al testimonio de Cupín.

El afecto y la cercanía con otros hombres fueron parte del argumento en contra del honor de Barros. Algunos testigos afirmaron que el magistrado siempre fue bastante afectuoso con esclavos, indios y soldados. Por ejemplo, algunos testigos en Quito aseguraban que solía caminar de la mano con un soldado moreno. ${ }^{56}$ También, dentro del interrogatorio a su exesclavo Gómez, se recordó una ocasión en la que el esclavo estuvo enfermo. Preocupado por él, Barros le preguntó «¿cómo estas,

53 AGI, Escribanía 917B, f. 603.

${ }^{54}$ Ib.: f. 327-336.

55 Ib.: f. 344v-346v.

${ }^{56}$ AGI, Escribanía 917B, f.541v. 
mi vida?». ${ }^{57}$ Así, su afecto desmedido hacia otros hombres fue utilizado contra el oidor. De manera que ciertos comportamientos, pensados como homoeróticos, fueron en contra del discurso imperial del vir.

Por último, la virilidad sexual fue la más afectada con esta parte de la acusación. La sexualidad de Barros fue muy diferente a la de sus contemporáneos en las Indias. Nunca contrajo matrimonio y no se le conoció ningún amancebamiento durante sus treinta ańos como oidor en el Nuevo Mundo. Sin embargo, Ortiz de Valdelomar, su abogado defensor, argumentó que el doctor no cometía el pecado nefando, pues, cuando tuvo necesidades sexuales, se acostaba con una esclava llamada Gerónima. ${ }^{58}$ Con ello, el procurador pretendía mostrar a Barros como un hombre de una sexualidad controlada. Sin embargo, los testimonios en su contra lo presentan constantemente como aficionado a los deseos de la carne. Por ejemplo, los vecinos de Quito hablaban del excesivo cariño que le profesaba a un esclavo llamado Cristóbal, quien después aseguraría que su dueño era «bujarrón». 59

La virilidad de Barros fue cuestionada con la fuerza de sus acciones. La acusación de Cupín fue la prueba más sólida sobre la sexualidad nefanda del magistrado. Los testimonios en su contra sirvieron para construir una imagen de Barros como la antítesis del discurso imperial sobre la masculinidad. Por esta razón, esta acusación fue capaz de abrir un proceso contra un personaje tan encumbrado de la sociedad colonial.

\section{PEDRO GÓMEZ, RUMORES Y MALA FAMA}

La segunda parte de la acusación se enfocó en la relación de Barros con Pedro Gómez, su exesclavo. En Panamá, supuestamente, Barros cometió el nefando crimen con él. Esta acusación tiene como particularidad el carecer de testigos. Todas las declaraciones presentadas se escucharon de terceros, por lo que se sustenta en rumores sobre la cercanía del esclavo

\footnotetext{
${ }^{57}$ Ib.: f. 325.

${ }^{58}$ Ib.: f. 368.

${ }^{59}$ Ib.: f. 544 .
} 
y su dueño. ${ }^{60}$ Así mismo, para 1594, circularon, en Charcas y Quito, antiguos y nuevos rumores en torno a sus amistades ilícitas. Por esto, ellos tuvieron un papel trascendental en el desarrollo del litigio.

De acuerdo con Tamar Herzog, a finales del siglo XVI, la fama fue fruto del sistema de honor y de la opinión pública. Fue un mecanismo de control basado en estereotipos según la posición del individuo en la escala social; una construcción moral fundada en la disciplina social, que incluía reglas de comportamiento. Este sistema tuvo como objetivo ordenar y mantener el equilibrio de la sociedad. Asimismo, en ciertas ocasiones, la fama cooperó en el desarrollo de los procesos judiciales. ${ }^{61}$ En el caso de Barros, la mala fama jugó en su contra dentro del proceso.

En general, los rumores representaron un gran porcentaje de las acusaciones contra Barros. Como se ha indicado antes, el rumor sobre las relaciones de Barros y Gómez circuló en Panamá hasta el punto de ser difundido en unos libelos en la plaza principal y sus alrededores. La denuncia del fiscal aseveraba que "estaba tan divulgado y entendido" el pecado nefando, debido al tratamiento y amor que el doctor profesaba a su esclavo. ${ }^{62}$ Gracias a las declaraciones del mismo Gómez es posible comprobar que la continua circulación de estos rumores. Este esclavo afirmó que algunas mujeres le increpaban, en algunas ocasiones, este delito. ${ }^{63}$

Dentro de la carrera de Barros, se observa cómo el tránsito de los rumores se va desarrollando de dos maneras. Por un lado, el rumor de Panamá se reproduce en otras audiencias. Como afirman Allport y

${ }^{60}$ Se entiende por rumor una afirmación no verificada de importancia instrumental que aparece en contexto de amenaza o peligro. Además, el rumor es una expresión oral que corre sin medios probatorios. Tiene como objetivo agraviar al sujeto odiado y con ello satisfacer una rencilla previa. No obstante, el rumor no puede ser una creación al azar; este debe tener una cercanía con la realidad para ser una aseveración creíble. De esta manera, este concepto es una representación de la realidad, distorsionada, exagerada algunas veces, con el objetivo de dañar (Di Fonzo y Bordia 2007; Allport y Postman 1988; Guerin 2003).

${ }^{61}$ Herzog 1995: 266.

${ }^{62}$ AGI, Escribanía 917B, f. 360.

${ }^{63}$ Ib.: f. 330. 
Postman, los rumores aparecen nuevamente y multiplican su mordacidad en momentos socialmente críticos. ${ }^{64}$ Por ello, en La Plata y Quito, las habladurías rondan, precisamente, en periodos de tensión política. En Charcas, tanto Tomás Luis, vecino de la ciudad, como el capitán Rodrigo de Esquivel aseguraron que era de conocimiento público que Barros había cometido el nefando crimen en Panamá. ${ }^{65}$ Estos testimonios se encuentran en la visita de Diego de Zúniga a la Audiencia de La Plata en 1585, documento relacionado directamente con las disputas entre Barros, Matienzo y Toledo. Los testimonios de Quito, recogidos a raíz de la crisis de la alcabala, también afirmaron el conocimiento de estos acontecimientos. De forma que los detractores de Barros buscaron, constantemente, mantener vivo el rumor sobre sus prácticas sexuales.

Es necesario precisar que el origen de los rumores fue diverso. De un lado, aquellos testigos que estuvieron presentes en Panamá son quienes participaron de las primeras murmuraciones. También estaban los creados por los testigos de Charcas, quienes afirmaron la veracidad de los libelos, tomando como única prueba la cercanía de Barros con Gómez. Por último, a todos ellos se sumaron los vecinos de Quito, quienes aseguraron todas las habladurías sin más pruebas que el comportamiento público de Barros.

Este origen corresponde, además, al contexto de tensión política en el que se desarrollaron los chismes. En Panamá, la aparición de los libelos está relacionada con el maltrato de Barros a los encomenderos locales y las constantes quejas enviadas a la metrópoli en su contra. En Charcas y Quito, la veracidad con que se tomó el rumor fue proporcional a la progresiva enemistad política con Barros. Por su parte, en Charcas, los rumores y su primera acusación por sodomía llegaron en el desarrollo de las disputas con Matienzo y Toledo. En Quito, las habladurías sobre Gómez fueron tomadas como ciertas, en paralelo, a la creciente disputa del presidente de la audiencia y el cabildo. Por ello, es claro el vínculo de los rumores con las disputas políticas en cada jurisdicción.

${ }^{64}$ Allport y Postman 1988: 9.

${ }^{65}$ AGI, Escribanía 917B, f. 561v; f. 563v. 
Por otro lado, existió una proliferación de otros chismes alrededor de sus prácticas sodomíticas. Estos crearon relaciones entre Barros con esclavos, soldados y hasta animales. Así, en la Audiencia de La Plata, los rumores acerca del pecado nefando entre el magistrado y Gómez aumentaron. Además, aparecieron nuevos encuentros entre ambos. Se decía que, en cierta ocasión «torno a reincidir y cometer con él, el dicho delito y era tan su querido el dicho negro que le vieron una vez al dicho doctor Barros que estaba en la caballeriza sentado sobre una pesebrera y tenía hechado un brazo sobre el pescuezo del dicho negro y asida de la otra mano». ${ }^{66}$

En Quito, la situación fue mucho peor, pues fueron múltiples los rumores acerca de las relaciones sexuales del presidente de la Audiencia. María de Aguilar, vecina de la ciudad, dijo haber escuchado públicamente que Barros había cometido el pecado nefando con un soldado apellidado Mendoza. También, Gómez Estacio de Barreda sostuvo que muchas personas en la ciudad afirmaban que Barros quería mucho a una perra, con la que compartía la cama. Lo cierto es que, la mascota del doctor Barros tenía un lugar preeminente en las casas de la Audiencia junto a su amo. Por último, su esclavo Cristóbal dijo que «el dicho doctor Barros, su amo, era un bujarrón. Que hecha a la perra braca en su cama y que el tiro que le había hecho era porque le había prometido darle libertad». ${ }^{67}$

Barros convivió, en principio, con la enemistad de un sector de la sociedad y, finalmente, con el odio y el rencor de gran parte de la población quiteña (oidores, cabildantes y gente del común). Los rumores confirman el resentimiento de la población y se convirtieron en la vía de escape de las rencillas políticas en los que fueron concebidos. Barros, progresivamente, adquirió la fama de sodomita. Esta mala imagen le jugaría en contra dentro del proceso abierto en Lima, ya que fue utilizada como argumento para afirmar su culpabilidad.

La mala fama influenció en la apertura de su caso y en su desarrollo. Como afirma Herzog, en momentos de crisis o tensión social,

${ }^{66}$ AGI, Escribanía 917B, f. 360 v.

${ }^{67}$ Ib.: f. 544 r-v. 
las autoridades y la sociedad tendían a instrumentalizar la fama para responsabilizar de una situación a determinado individuo. ${ }^{68}$ En consecuencia, la utilidad de la imagen dependió de cuán desprestigiado estuviese el sujeto. La buena fama bloqueaba los indicios; en cambio, la mala facilitaba la denuncia y otorgaba mayor solidez a las pruebas. ${ }^{69}$

Las disputas con los oidores, el cabildo y su mala fama generaron que la responsabilidad en torno a la crisis por la imposición de las alcabalas le fuese enteramente atribuida. Es por ello que, en el peor momento de la crisis, entre diciembre de 1592 y enero de 1593, el odio contra Barros y los rumores de sus prácticas sexuales llegaron a su punto más alto. Si Barros hubiese mantenido un buen nombre y prestigio, se hubiese logrado desmentir el testimonio de Cupín. Fueron los rumores de Panamá, Charcas y Quito los que dieron pie a que las acusaciones del esclavo fueran atendidas por el alcalde ordinario Pedro de Santillán.

Un sistema judicial movido por la fama trataba de manera distinta a los acusados. ${ }^{70}$ En ese sentido, se tenía mayores consideraciones con personajes encumbrados de la sociedad colonial debido a su calidad. A pesar del pedido expreso de la Corona, la comisión encargada procedió de forma imprudente y de forma tendenciosa. La detención y la confiscación de sus bienes, en 1593, fue prueba de ello, pues las evidencias en contra de Barros eran dudosas. Cupín se había retractado frente a sus cuatro confesores; y Gómez y Marroquí no habían confesado haber mantenido relaciones sexuales con el magistrado. Claramente, las retractaciones del esclavo fueron un inconveniente para la comisión, pues no permitían consolidar adecuadamente el cauce judicial. Pese a ello, la acusación formal del fiscal muestra cómo las sospechas fueron convertidas en pruebas fidedignas.

A lo largo del proceso, fueron reiteradas las veces en que se mencionó la mala fama de Barros. Por una parte, su defensa se preocupó por dejar constancia de que esta mala imagen fue consecuencia de las enemistades por su trabajo en Panamá y Charcas. De las treinta y nueve preguntas

\footnotetext{
${ }^{68}$ Herzog 1995a: 270.

${ }^{69} \mathrm{Ib} .: 269$.

${ }^{70}$ Herzog 1995a: 265.
} 
elaboradas por el procurador Ortiz de Valdelomar, veintiuna estuvieron relacionadas con las habladurías en torno a Barros, y tres de ellas buscaban presentarlo como un hombre correcto. ${ }^{71}$ Por otra parte, la comisión buscó reconstruir todos los rumores y habladurías en las que se basaba esta mala fama. Esto último con el objetivo de confirmar su delito. Por esta razón, una de las primeras órdenes fue la captura y el traslado a Lima de los esclavos Gómez y Marroquí. Ellos eran claves para sostener el caso después del arrepentimiento de Cupín. Además, el interrogatorio y los testigos del fiscal afirmaron, en mayor o menor medida, las acusaciones contra Barros. En consecuencia, los rumores y la mala fama de Barros perjudicaron su defensa contra el nefando crimen.

\section{GARCÍA SÁNCHEZ Y LA MALA JUSTICIA}

La tercera acusación contra Barros se centró en el cumplimiento de sus funciones judiciales. Dentro de la investigación, el fiscal identificó que Barros había dejado libres a dos acusados por sodomía en la Audiencia de Charcas. Incluso, uno de ellos, García Sánchez, había sido designado para tomar cuenta de bienes de difuntos. A través de la parte final de la acusación, es posible evidenciar la relación entre la mala práctica de la justicia y su vinculación con la hombría. Con ello, la argumentación fiscal propuso que su práctica sexual condicionó su labor como autoridad real.

En el mundo colonial hispano, la experiencia judicial montó sus propias lógicas con respecto a la justicia, el juez y la ley. Para José de la Puente, el impartir justicia dependía de los criterios individuales del juez, teniendo como objetivo mantener el equilibro y la tranquilidad social. Por este motivo, el magistrado debió caracterizarse por virtudes personales y no necesariamente por el estudio de las leyes. ${ }^{72}$ Corpus jurídicos, como Las siete partidas, Leyes de Toro o Leyes Nuevas existieron como un espacio de referencia, donde se evidenciaba la peligrosidad de cada delito. Sin un marco procesal que seguir, el juez debía actuar según su criterio. ${ }^{73}$

\footnotetext{
${ }^{71}$ AGI, Escribanía 917b, f 571v- 575v.

72 Puente Brunke 2008: 67.

${ }^{73}$ Herzog 1995 b.
} 
El Iudex Perfectus fue el ideal que debían alcanzar los presidentes de audiencia y oidores, pues su misión era la de aplicar de manera justa y equitativa las leyes dictadas por la Corona. Por tanto, la justicia dependía, principalmente, del comportamiento justo. La legitimidad de una adecuada justicia y la autoridad estuvo centrada en la ética del magistrado. Por ello, fue trascendental que, dentro de su jurisdicción, las autoridades fueron percibidas como hombres prudentes. ${ }^{74}$ Con el objetivo de mantener su imagen de buen juez, los magistrados dependían de terceros, es decir, sus compañeros de audiencia, autoridades eclesiásticas, el cabildo, caciques y, en general, de toda la opinión pública. Muchas veces, estos comentarios servían como punto de apoyo para la promoción de los burócratas en su carrera, pero también sirvió para frenarlos.

El 6 de julio de 1593, en una larga carta al virrey marqués de Cañete, Barros expuso su preocupación por su imagen como juez «porque quiero el favor de vuestra excelencia para cosas más graves, y en España, que esta visita, aunque en el proceder den pesadumbre no pueden producir cosas más graves en el fin honra y gloria para quien también como yo ha servido al rey». ${ }^{75}$

Su preocupación resultó ser evidente, con un juicio previo, el oidor debía cuidar su imagen frente a la Corona. Barros entendió que el nuevo proceso estaba dirigido directamente contra su imagen. De esta forma, reconoció que el nefando crimen puso en jaque su posición y sus aspiraciones políticas.

En contraste, el mal juez era percibido como el hombre guiado por sus pasiones. El temor, la codicia, el odio y el amor desmedido nublaban la misión del magistrado, porque su ser privado se imponía ante el público. ${ }^{76}$ Entre los principales delitos de un mal juez, se encontraban la protección de delincuentes y el desborde de las pasiones sexuales. ${ }^{77}$ En ese sentido, los acusadores de Barros pretendieron presentarlo como un mal juez. Por una parte, la acusación central en su contra fue cometer

\footnotetext{
${ }^{74}$ Puente Brunke 2008.

75 AGI, Escribanía 917B.

76 Puente Brunke 2008: 66.

77 Mantecón 2002.
} 
el pecado nefando con Cupín. El fiscal expuso, detalladamente, como Barros mantuvo relaciones sexuales con el esclavo por algunos meses. Con este discurso, se quiso demostrar que el presidente de la Audiencia de Quito vivía preso de sus pasiones, las cuales fueron consideradas como actos contra su cargo, el rey y Dios.

Siendo dudoso el testimonio de Cupín, el fiscal intentó conseguir otras declaraciones del nefando crimen. Fundamentalmente, porque necesitaba pruebas sólidas y testigos de primera mano. Por esta razón, precisó extender el tiempo de investigación y la petición de un término ultramarino. ${ }^{78}$ Además, con la expansión de la investigación a Panamá, Charcas y Quito se buscó dilatar el caso.

Durante esta búsqueda, se encontraron dos testimonios que demostraban, en opinión del fiscal, los excesos sexuales de Barros en La Plata y Quito. La primera fue la declaración de Tomas Luis, vecino de Charcas. Este testigo visitó a Barros durante su cautiverio en un monasterio franciscano debido a su primer proceso. En esta reunión, aseguró haberlo visto muy afectuoso con Gómez. Según Luis, antes de llegar a la habitación del doctor, escuchó risas y «dar palmadas como que daban a la carne». ${ }^{79}$ $\mathrm{Al}$ entrar al recinto, encontró al negro echado en un extremo de la cama $y$ al doctor sin camisa en la otra. ${ }^{80}$

En Quito, la confesión de Aguilar y de su hermano, Bernardino de Parada Hinojosa, resaltaron el mal comportamiento del magistrado incluso en la misma sede de la Real Audiencia. Ellos aseguraron haber visto que

llegó a hablar al dicho doctor Barros un soldado que se llama [Baltazar de] Lerma que era jugador, hombre moreno y alto de cuerpo. llevaba en las manos un frasco de plata y le dijo, el dicho Lerma, «mire que lindo frasco he ganado y lo traigo lleno de vino que no lo quise traer vacío, ven» y el dicho doctor Barros respondió diciendo "quitaos allá» y el dicho Lerma dijo "quítese allá» y esto decían dándose el uno al otro con las manos en el cuerpo y riéndose. Y el dicho doctor Barros dijo "pues yo no tengo muy

\footnotetext{
${ }^{78}$ AGI, Escribanía 917B, f. 361 v.

${ }^{79}$ Ib.: f. 562

${ }^{80}$ Ib.: f. 360 v.
} 
buen vino» y el dicho Lerma le porfió que viniese por que puso el dicho Lerma el frasco en la boca como que bebía y luego volvió a porfiar con el dicho Barros que bebiese el cual no quiso y tomó de la mano al dicho Lerma y le metió dentro en el aposento donde tenía su cama que es otro más a dentro de donde estaban. ${ }^{81}$

Estos dos testimonios representaban a Barros como un irremediable sodomita, un magistrado preso de sus deseos. Alguien que profanaba dos lugares dedicados, directa o indirectamente, a Dios: el monasterio y la Real Audiencia.

Por otra parte, se le acusaba de favorecer sodomitas confesos y darles libertad en la ciudad de La Plata:

estando preso por el mismo delito un García Sánchez, vecino de Cumaná, le favoreció mucho el dicho doctor Barros y le hizo soltar de la cárcel y le dio una comisión para tomar una cuenta de bienes de difuntos. Y estando, asimismo, preso un negro por el pecado nefando, en la cárcel de la dicha real audiencia. Y habiendo confesado el dicho delito ante el dicho doctor Barros detuvo muchos días y le enviaba de comer hasta que se huyó el dicho negro. Se fue a Tucumán, donde torno a reincidir en el dicho pecado y le quemaron allá por ello. ${ }^{82}$

Barros era cuestionado como magistrado a través del nefando delito. El fiscal finalizó con esta acusación, ya que su objetivo fue exponer que, gracias a sus inclinaciones sodomíticas, Barros protegía a los que tenían su misma práctica sexual. Sus enemigos presentaron evidencia, real o fabricada, para argumentar que su cercanía a los crímenes de índole sexual interfirió en su labor como juez cuando era oidor en Charcas. Así, se dejaba abierta la posibilidad de que su mala justicia pudiera haberse realizado en otras jurisdicciones bajo su gestión.

Barros fue infamado más allá de su hombría, ya que fue cuestionado como juez. Asimismo, existió una retroalimentación entre el oficio y quien lo ejercía. En ese sentido, la imagen institucional se construía

${ }^{81}$ Ib.: f. 543; $545 \mathrm{r}-\mathrm{v}$.

${ }^{82}$ AGI, Escribanía 917B, f. 361. 
sobre la base de las dos figuras. ${ }^{83}$ Para el caso de Barros, sus crímenes lo sindicaban como un mal juez, guiado por sus deseos. Aquello había nublado su juicio, lo que provocó que diera libertad a criminales. En general, existió una búsqueda por exponer su mal criterio que, como se verá más adelante, muchos sindicaron como el principal problema en la crisis de las alcabalas. También, se pretendió confirmar sus malas prácticas sexuales y vincularlas con su trabajo como presidente de audiencia. Como consecuencia, más allá de purgar el pecado nefando de Barros, su objetivo primordial fue cuestionar formalmente su lugar como representante de la justicia.

\section{LAS CRISIS POLÍTICAS Y EL SODOMITA}

Los enemigos de Barros habían encontrado una forma de deshacerse de él en medio de la crisis política que este había creado. Crisis que inició, algunos años antes, con su nombramiento como presidente de la Audiencia de Quito en 1587. A su llegada, como primera tarea, Barros hizo una visita general de su nueva jurisdicción. Como resultado, encontró que el desprestigio de la Audiencia había consolidado el poder del Cabildo y de los encomenderos. ${ }^{84}$ Quito había permanecido sin un presidente fijo por diez años. Por esta razón, su objetivo principal debió ser recuperar la autoridad de la audiencia.

En el desarrollo de su visita, Barros llegó a la conclusión de que los magistrados deshonraban la institución. ${ }^{85}$ Los oidores y la elite local mantenían acuerdos que beneficiaron a ambos grupos de poder. Además, estas autoridades mantuvieron una vida poco moral fuera de las casas reales, que en muchos casos se relacionaron con apuestas y mujeres. Los oidores Pedro Venegas de Cañaveral, Francisco de Auncibay y Diego de Ortegón fueron encontrados culpables de muchos delitos.

En las cartas enviadas al Consejo de Indias, Barros fue muy crítico con el trabajo realizado por el licenciado Venegas de Cañaveral. De edad

\footnotetext{
${ }^{83}$ Herzog 1995: 123.

${ }^{84}$ Lavallé 1995.

${ }^{85}$ AGI, Quito 8, R. 25, N. 97.
} 
muy avanzada, Venegas fue culpado de no conocer la ley ni contar con la aptitud para hacerla valer. Incapaz de cumplir con su función, el mando fue delegado a su esposa, doña Magdalena de Anaya y Guzmán. Barros determinó a ambos como responsables de muchos delitos, entre los cuales se encontraba la venta de ilícita de alimentos, apuestas y juegos de azar. ${ }^{86}$

Ortegón, por su parte, fue descrito por Barros como una persona áspera y rigurosa.$^{87}$ Fue acusado de utilizar las visitas para cobrar salarios excesivos y tener acuerdos con algunos comerciantes por mano de obra indígena. Su sistemático maltrato a los naturales lo hizo responsable del levantamiento de los Quijos y del tráfico de indios para las minas e ingenios locales. Por último, Auncibay fue catalogado como el peor de todos ellos. Por un lado, Barros lo encontró culpable de recibir sobornos para favorecer a una de las partes en ciertos juicios. Aprovechando los litigios de la elite, amasó una fortuna gracias a la entrega de dinero y joyas de parte de algunos vecinos. Por otro lado, se le encontró responsable de inmoralidades de índole sexual. Barros aseguraba que Auncibay había mantenido relaciones ilícitas con mujeres de todo Quito, deshonrando renombradas familias. ${ }^{88}$

Asimismo, Barros criticó el trabajo de otras autoridades de la Audiencia que llegaron durante su gestión. Tanto el doctor Moreno de Mera y los fiscales Gaspar de Peralta y Morales Tamayo fueron duramente cuestionados por sus alianzas con la elite económica. ${ }^{89}$ Debido a esto, para 1591, toda la institución, y sus aliados en el Cabildo, odiaban a Barros.

Este sentimiento fue compartido por muchas personas en Quito. En un contexto más amplio, antes de la llegada de Barros, la localidad había superado una serie de desastres naturales y, en consecuencia, existía una baja en la economía regional. ${ }^{90}$ Barros generó mayores disputas por sus

\footnotetext{
${ }^{86}$ Ib.: R. 22, N. 63

${ }^{87}$ Lavallé 1997: 67.

${ }^{88}$ Auncibay fue acusado de múltiples relaciones sexuales ilícitas con mujeres de toda clase social en esta localidad. AGI, Quito 8, R. 22, N.63.

${ }^{89}$ Lavallé 1997.

${ }^{90}$ Entre las décadas de 1570 y 1580 , Quito fue azotada por una serie de cataclismos, erupciones de volcanes y epidemias. Esto afectó directamente a la población indígena.
} 
políticas proindígenas. Además de lidiar con la reducción de naturales, se aumentó la paga que debían recibir. Barros no solo había puesto un límite a la explotación, sino que había exigido que se respetasen las normas de trabajo de los naturales. ${ }^{91}$ De esta forma, la élite local, también, detestaba al presidente de la Audiencia.

Para 1592 el resentimiento contra Barros era evidente. Lamentablemente, todo empeoraría con la aplicación del impuesto de las alcabalas. Felipe II dispuso el pago del impuesto, pero en un 2 \%. Fueron exceptuados de su cobro los indígenas, los conventos y algunos artículos como pan, granos y alimentos vendidos al menudeo. La justificación real fue alrededor de los peligros y la protección de navíos ante corsarios. ${ }^{92}$

Tan pronto se informó el Cabildo, el procurador Alonso Moreno Bellido solicitó que la ciudad fuese exonerada de este cobro. El 15 de agosto, sin tomar en cuenta la petición de los cabildantes, se pregonó el impuesto, lo que generó malestar entre la población. Lejos de apaciguar la situación, Barros se burló repetidas veces de los vecinos que protestaron contra la imposición de este impuesto. Esta actitud fue trascendental para el proceso, pues marcaría el inicio de una crisis política. ${ }^{93}$

Cansados de la intransigencia de Barros, algunos vecinos de Quito tramaron el asesinato del presidente y los oidores. Una rápida acción de la Audiencia logró desbaratar al grupo de rebeldes. Sin embargo, esto no fue suficiente, pues, al poco tiempo, todos los pueblos de la región estaban dispuestos en armas para evitar el cobro de la alcabala. ${ }^{94}$ De esta

La caída demográfica de la localidad ocasionó un fuerte remezón en las dinámicas económicas de la zona. Para más información, véase Lavallé 1997: 32- 35.

${ }^{91}$ Barros comunica al Consejo, constantemente, su preocupación por la vida de los mitayos en la localidad. El 6 de abril de 1588 informó cómo había subido el sueldo a los mitayos debido al trabajo excesivo que realizaban sobre todo en los obrajes (AGI, Quito 8, R. 22. N.65; Quito 8, R. 23, N. 72; Quito 8, R. 2, N. 85).

${ }_{92}$ Lavallé 1997: 16.

${ }^{93}$ Según Lavallé, Barros, durante este primer momento, se burlaba públicamente del «licenciado Ximeno, abogado de la ciudad y regidor, Catalina Ximeno, a Joan de la Ve, Juan Caceta o Juan Camiseta, y a Moreno Bellido, el cacique de Turmequé, por el nombre del pueblo donde este había nacido». Para más información, véase Lavallé 1997: 147.

${ }^{94}$ Presos de sus culpas, uno de los rebeldes confesó sus acciones al dominico Fray Jerónimo de Mendoza, quien informaría a la audiencia de este posible atentado. A pesar de tener 
forma, Barros consiguió que Quito se uniera contra quien quisiera implementar el impuesto.

La tensión de los disturbios obligó al Marqués de Cañete, virrey del Perú, a enviar tropas. El desembarco del general Pedro de Arana llevó la crisis a un nuevo nivel, ya que los quiteńos capturaron a los oidores y exigieron la retirada de la armada. Para el 29 de diciembre de 1592, el presidente de la Audiencia había perdido el respeto de toda la población y los antiguos rumores en torno a su sexualidad regresaron. Según Lavallé, Quito vivía una fobia anti-Barros. La población lo acusaba indistintamente de un sinnúmero de delitos y pecados, pero el que más resaltó fue la acusación de sodomita. ${ }^{95} \mathrm{El} 4$ de enero del siguiente ańo, la Audiencia de Lima ordenó que Barros fuera apresado y que se le confiscaran sus bienes a razón de las declaraciones de Cupín sobre sus prácticas sodomíticas. ${ }^{96}$

La gravedad de los sucesos quiteños generó malestar en la capital virreinal. El Marqués de Cañete, en un primer momento, tuvo una muy buena impresión de Barros. ${ }^{97}$ No obstante, el 15 de enero de 1593, Hurtado de Mendoza había cambiado totalmente su parecer. La hostilidad entre estas dos autoridades llegó al punto de que Barros acusó a Cañete de ser uno de los promotores de la causa por sodomía que tenía en Lima. Principalmente, porque, a pesar de tener el permiso del Consejo de Indias para regresar a Castilla bajo fianza, la comisión investigadora insistió que debía presentarse en Lima. ${ }^{98}$

En el caso de Quito, el resentimiento contra el presidente de la Audiencia fue un proceso concatenado de disputas entre la autoridad y los poderes locales. Las constantes peleas entre Barros, los oidores y la élite fueron el germen de la crisis. La acelerada maduración de la alcabala fue el espacio de tensión necesario para que apareciera una acusación por sodomía. Por esta razón, en Lima se abrió el segundo proceso contra el

todos identificados, solo fue encarcelado Moreno de Bellido (Lavallé 1997: 151-153).

${ }^{95}$ Lavallé 1997.

${ }^{96}$ AGI, Escribanía 917B, f. 338v.

${ }^{97}$ Levillier 1921-1926, XI: 310.

${ }^{98}$ AGI, Escribanía 917B, f. 344-346v. 
Barros. Este juicio sería la suma de enemistades del magistrado unidas con un propósito: eliminarlo de las Indias.

\section{DE MANOS ATADAS}

Durante el siglo XVI, España había construido su imagen como guardián de la fe; por esta razón, el pecado nefando debió ser una preocupación de las autoridades tanto en la metrópoli como en sus territorios ultramarinos. A pesar de que la corona estuvo obligada a castigar con dureza este delito, muchas veces fueron factores sociales y políticos los que determinaron la severidad de la pena. ${ }^{99}$ En casos como el de Barros, su posición como autoridad real le permitió escapar de una primera acusación. No obstante, el cúmulo de rumores y su mala fama, junto a las enemistades políticas, permitieron juzgar al burócrata, nuevamente. Barros representó un problema mayor, ya que su delito constituía una transgresión inaceptable y puso en tela de juicio el criterio real para la elección de sus representantes.

Asimismo, la monarquía hispana busco centralizar su poder. Con ello, en el Nuevo Mundo se estableció un sistema clientelar, donde la autoridad colonial se sustentaba en las mercedes que recibía del rey un individuo. El orden político se compuso de una red clientelar que sirvió para legitimar la autoridad y el ejercicio de poder de virreyes, gobernadores, oidores, etc. Los cargos administrativos fueron manifestaciones públicas de la relación entre el monarca y sus mandos. ${ }^{100}$ De manera que, las faltas y los aciertos de estos burócratas afectaron la imagen de la corona en América.

Para 1590, Barros era un personaje perjudicial en el mundo colonial y, en específico, en la Audiencia de Quito. Su trabajo no fue bien recibido, localmente, por evidenciar el mal quehacer de la audiencia y exponer sus vínculos con la elite. A este odio, se sumó el resentimiento de los quiteños por su favoritismo con los indígenas. Incapaz de aceptarlo, Barros no se mostró dialogante con los poderes locales, pues creía que la autoridad

99 Molina 2014a

${ }^{100}$ Costa 2016. 
concedida por la monarquía era suficiente para hacer cumplir sus decisiones. En consecuencia, el nefando crimen fue el recurso con el cual lo grupos de poder político respondieron a las imposiciones de Barros. A través del juicio por sodomía, se evidenció la incapacidad de Barros de ser un adecuado representante real. Trascendiendo la moralidad del pecado, un juez cuestionado afectaba la imagen de la monarquía. El caso fue, sin duda, el argumento más fuerte contra la continuidad de Barros como burócrata del imperio. Su práctica sexual no solo lo desprestigiaba a él, sino también a la audiencia. Por esto, se rompe la relación clientelar entre Barros y el monarca, pues no cumplía con uno de los objetivos de su cargo: afianzar el lugar de la corona. La monarquía cuidó en todo momento su imagen frente a sus súbditos; sobre todo en un contexto como el americano, donde la lejanía generaba cierta pérdida de poder. El monarca se vio obligado a restablecer el orden y eliminar todo tipo de cuestionamiento. No obstante, no se podía encontrar públicamente culpable a Barros, pues, el reconocimiento de esta sentencia significaría aceptar el error en las elecciones de la Corona. En otros casos, el perdón real restauraba al juez en su mal uso de la justicia; ${ }^{101}$ sin embargo, la gravedad del delito no lo permitía. Tomando en cuenta su posición social, Barros solo fue desterrado de las Indias y confinado al hogar familiar.

\section{CONCLUSIONES}

Aunque la persecución contra Barros se justificó en su transgresión de la religión y la ley, tuvo un objetivo meramente político. La aparición de acusaciones de travestismo y sodomía fueron frecuentes en las disputas políticas. El pecado que no debe ser nombrado fue utilizado como arma debido a las consecuencias que traía al inculpado, quien podría sufrir desde azotes hasta la muerte. Para Barros, el costo fue el destierro y el pago de 7000 ducados.

Las tres partes de la denuncia estuvieron pensadas para evidenciar la trascendencia de su delito. Su relación con Andrés Cupín fue la prueba principal de prácticas poco masculinas. Además, lo acontecido con Pedro

${ }^{101}$ Mantecón 2002: 88. 
Gómez sirvió para exponer la mala fama que llevaba Barros. Finalmente, el caso de García Sánchez constataba que su sexualidad se había inmiscuido en su labor judicial. En opinión de sus críticos y acusadores, la sodomía no solo afectaba moralmente a Barros, sino que también llegó a comprometer su trabajo como oidor de la corona.

Barros perdió la contienda política contra sus enemigos porque su imagen estaba totalmente desprestigiada, lo que lo convirtió en un lastre para la monarquía hispana. Su actividad sexual era lo que había disminuido su capital social, y contribuyó con ello al desprestigio de la justicia real. El soporte que debía brindar el clientelismo monárquico quedó obstaculizado por el nefando crimen. La única respuesta posible para un personaje como Barros fue separarlo del cargo. No obstante, no se le abandonó a su suerte, pues Barros no recibió la pena máxima para esta clase de delitos. El tratamiento del caso se convierte en una cuestión particular del Consejo de Indias. Después de librarse de una sentencia como la de Andrés Cupín, el doctor Barros quedó totalmente deshonrado, como queda en evidencia por su carta de 1596. En ella, Barros daba cuenta de su carrera al servicio de la corona y suplicaba al rey la restitución de su honra destruida por el caso de Lima. Lamentablemente, su pedido nunca recibió respuesta.

\section{Bibliografía}

Allport, Gordon y Leo Postman. 1988. Psicología del rumor. Buenos Aires: Psique. Archivo Biográfico de Ecuador. Barros de San Millán, Manuel. http://www.archivobiograficoecuador.com/tomos/tomo1/Barros-de-San-Millan-Manuel.htm (Consulta enero 2015).

Bermúdez Plata, Cristóbal. 1940-1986. Catálogo de pasajeros a Indias: durante los siglos XVI, XVII y XVIII. Sevilla: Edición de la Gavidia y Ministerio de Cultura, 7 vols.

Burkholder, Mark. 1999. "Honor and honors in colonial Spanish America». En Johnson, Lyman y Sonya Lipsett-Rivera (eds.). The Faces of Honor. Sex, Shame, and Violence in Colonial Latin America. Albuquerque: University of New Mexico Press, 18-44.

Camba, Úrsula. 2011. «El pecado nefando en los barcos de la carrera de Indias en el siglo XVI». En Roselló, Estela (coord.). Presencias y miradas del cuerpo en 
la Nueva España siglos XVI-XVIII. Ciudad de México: Universidad Nacional Autónoma de México,109-133.

Clavero, Bartolomé. 1990. «Delito y pecado: noción y escala de transgresiones». En Tomás y Valiente, Francisco (coord.) Sexo Barroco y otras transgresiones pre modernas. Madrid: Alianza Editorial, 57-89.

Connell, Raewyn. 2003. Masculinities. Berkeley: University of California Press.

Connell, Raewyn. 2016. «¿Prácticas corruptas o relaciones de patronazgo? Orden patrimonial y la naturaleza del sistema político en el Perú colonial durante el gobierno del virrey conde del Villar (1585-1590)». En Rosenmüller, Christoph y Stephan Ruderer (eds.). Dadivas, dones y dineros. Aportes a una nueva historia de la corrupción en América Latina desde el imperio español a la modernidad. Madrid: Iberoamericana/Veruert, 27-55.

Costa, Miguel. 2016. «Prácticas corruptas o relaciones de patronazgo. Orden patrimonial y la naturaleza del sistema político en el Perú colonial durante el gobierno del virrey conde del villar (1585-1590)». En Rosenmüller, Christoph y Stephan Ruderer (eds.), Dádivas, dones y dineros. Aportes a una nueva historia de la corrupción en América Latina desde el imperio español a la modernidad. Madrid: Iberoamericana/Vervuert, 27-55

Di Fonzo, Nicholas y Prashant Bordia. 2007. Rumor psychology: social and organizational approaches. Washington, D. C.: American Psychological Association. https://doi.org/10.1037/11503-000

Enciclopedia del Ecuador. Dr. Manuel Barros de San Millán. http://www.enciclopediadelecuador.com/personajes-historicos/dr-manuel-barros-de-san-millan/ (consultado en enero 2015)

Garza, Federico. 2002. Quemando mariposas. Sodomía e imperio en Andalucía y México siglos XVI-XVII. Barcelona: Laertes.

Ghirardi, Mónica. 2009. «El matrimonio, el Concilio de Trento en Hispanoamérica». Revista de Indias. Volumen LXIX, número 246: 241-272. https://doi. org/10.3989/revindias.2009.020

Giraldo, Carolina. 2001. «Esclavos sodomitas en Cartagena colonial. Hablando del pecado nefando». Historia Critica. Núm. 20: 171-178. https://doi.org/10.7440/ histcrit20.2000.06

González, Óscar. 2015. «El pecado de sodomía en los siglos XV y XVI: entre la herejía europea y la idolatría indiana». En Guerrero Guerrero, Ana Luisa (coord.) Dignidad intercultural. Ciudad de México: Centro de Investigaciones sobre América Latina y el Caribe, 131-154.

Guerin, Bernard. 2003. «Rumores, chismes y leyendas urbanas: una teoría de contingencia social». Revista latinoamericana de psicología. Volumen 35, número 3: $257-272$. 
Herzog, Tamar. 1995a. La administración pública como fenómeno social: la justicia penal de la ciudad de Quito (1650-1750). Madrid: Centro de Estudios Constitucionales.

Herzog, Tamar. 1995b. «Sobre la cultura jurídica en la América colonial (siglos XVI-XVIII)». Anuario de Historia del Derecho Español. Número. 65: 903-911. Jordan, Mark. 2002. La invención de la sodomía en la teología cristiana. Barcelona: Laertes Ediciones.

Lavallé, Bernard. 1997. Quito y la crisis de la Alcabala (1580-1600). Quito/Lima: Corporación Editorial Nacional e Instituto Francés de Estudios Andinos. https:// doi.org/10.4000/books.ifea.2766

Levillier, Roberto. 1921-1926. Gobernantes del Perú: cartas y papeles, siglo XVI. Madrid: Sucesores de Rivadeneyra; Juan Pueyo, 14 vols.

Levillier, Roberto. 1922. La Audiencia de Charcas: correspondencia de presidentes y oidores: documentos del Archivo de Indias. Madrid: Imprenta de Juan Pueyo, 3 vols.

Mantecón, Tomas. 2002. «El mal uso de la justicia en la Castilla del siglo XVII». En Fortea, José (ed.). Furor et rabies. Violencia, conflicto y marginación en la Edad Moderna. Santander: Universidad de Cantabria, 69-98.

Medina, Rubén. 2004. «Masculinidad, imperio y modernidad en Cartas de relación de Hernán Cortés». Hispanic Review. Volumen 72, número 4: 469-489.

Molina, Fernanda. 2010a. "La herejización de la sodomía en la sociedad moderna. Consideraciones teológicas y praxis inquisitorial». Hispania Sacra. Volumen LXII: 539- 562. https://doi.org/10.3989/hs.2010.v62.i126.258

Molina, Fernanda. 2010b. «Los sodomitas virreinales: entre sujetos jurídicos y especie». Anuario de Estudios Americanos. Volumen 67, número 1: 23-52. https:// doi.org/10.3989/aeamer.2010.v67.i1.330

Molina, Fernanda. 2011. «Crónica de la hombría. La construcción de la masculinidad en la conquista de América». LEMIR. Número 15: 185-206.

Molina, Fernanda. 2013. «El convento de Sodoma. Frailes, órdenes religiosas y practicas sodomíticas en el virreinato del Perú (siglo XVI-XVII)». Histoire(s) de l'Amérique Latine. Número 9: 1-17.

Molina, Fernanda. 2014a. «Entre la doble vara y el privilegio. La administración de justicia frente al fenómeno de la sodomía masculina en el virreinato del Perú (siglo XVI-XVII)». Revista de Indias. Volumen LXXIV, número 261: 361-385. https://doi.org/10.3989/revindias.2014.012

Molina, Fernanda. 2014b. «Femina cum femina. Controversias teológicas, jurídicas y médicas en torno a la sodomía femenina en el mundo hispano (Siglos XVIXVII)». ARENAL. Volumen 21, número 1: 153-176.

Molina, Fernanda. 2017. Cuando amar era pecado. Sexualidad; poder e identidad entre los sodomitas coloniales (Virreinato del Perú, siglos XVI-XVII). La Paz: Instituto Francés de Estudios Andinos y Plural Editores. 
Murra, John. 1998. «El doctor Barros de San Millán, defensor de los «señores naturales» de los Andes». Actas del IV congreso internacional de etnohistoria. Volumen 2. Lima: Pontificia Universidad Católica del Perú, 426-438.

Novísima recopilación de las leyes de España mandada formar por el Señor Don Carlos $I V$. 1846. París: Librería de don Vicente Salva. 5 vols.

Puente Burnke, José de la. 2008. «Notas sobre el funcionamiento de la Audiencia de Lima a mediados del siglo XVII». En Puente Brunke, José de la y Jorge Armando Guevara Gil (eds.). Derecho, instituciones y procesos históricos. XIV Congreso del Instituto Internacional de Historia del Derecho Indiano. Vol. I Lima: Pontificia Universidad Católica del Perú e Instituto Riva-Agüero, 507-516.

Ramos, Isabel. 2004. «La represión de los delitos atroces en el derecho castellano de la edad moderna». Revista de Estudios Histórico-Jurídicos. Número XXVI, 255-299.

Redworth, Glyn. 2004. «Castro, Alfonso de (c.1495-1558)». En Cannadine, David (ed.). Oxford Dictionary of National Biography. Oxford: Oxford University Press. http://www.oxforddnb.com/view/article/4873 (consultado Noviembre 23, 2016).

Reyes, Guillermo de los. 2010. «Curas, dones y sodomitas: sexual moral discourses and illicit sexualities among priests in colonial Mexico». Anuario de Estudios Americanos. Volumen 67, número 1: 53-76. https://doi.org/10.3989/ aeamer.2010.v67.i1.332

Seed, Patricia. 1991. Amar, honrar y obedecer en el México colonial: Conflictos en torno a la elección matrimonial, 1574-1821. Ciudad de México: Alianza Editorial.

Stavig, Ward. 2003. «Political abomination and private reservation: the nofarious sin, homosexuality, and cultural values in Colonial Peru». En Sigal, Pete (ed.), Infamous desire. Male homosexuality in Colonial Latin America. Chicago: University of Chicago Press, 134-151.

Tomás y Valiente, Francisco. 1990. «El crimen y pecado contra natura». En Tomás y Valiente, Francisco (coord.). Sexo barroco y otras transgresiones pre modernas. Madrid: Alianza Editorial, 105-128.

Tomás y Valiente, Francisco. 1997. "El derecho penal de la monarquía absoluta». Obras Completas, Tomo I. Madrid: Centro de Estudios Políticos y Constitucionales, 185- 546.

Vargas, José María. 1977. Historia del Ecuador: siglo XVI. Quito: Pontificia Universidad Católica del Ecuador.

Fecha de recepción: 16/VII/2020

Fecha de aceptación: 20/IX/2020 